\title{
A systematic review and quality appraisal of bereavement care practice guidelines
}

\section{Running Title}

Quality appraisal of bereavement care practice guidelines

\section{Authors}

Katherine Kent ${ }^{1 *}$, Belinda Jessup ${ }^{1}$, Pauline Marsh ${ }^{1}$, Tony Barnett ${ }^{1}$, Madeleine Ball ${ }^{2}$

1. Centre for Rural Health, College of Health and Medicine, University of Tasmania, Tasmania, Australia

2. School of Health and Biomedical Sciences, RMIT University, Melbourne, Australia

\section{${ }^{*}$ Correspondence}

Katherine Kent, Centre for Rural Health, School of Health Sciences, College of Health and Medicine, University of Tasmania, Locked Bag 1322, Launceston, TAS 7250; Email:

Katherine.kent@utas.edu.au

\section{Abstract}

Bereavement care practice guidelines assist in delivering high-quality bereavement care. However, the quality of published guidelines is unknown. A systematic review was conducted to identify and evaluate the quality of the process used to develop bereavement care practice guidelines using the Appraisal of Guidelines for Research and Evaluation (AGREE II) instrument. A key word search was conducted in MEDLINE-Complete, CINAHL-Complete, Health-Source (Nursing/Academic Edition), Psychology \& Behavioral Sciences Collection, and an internet search engine in October 2017. Sixteen guidelines with differing scope and purpose but similar core values were identified from the grey literature and then appraised at high quality $(n=1)$, moderate quality $(n=4)$ or low quality $(n=11)$. The domains 'clarity of presentation' and 'scope and purpose' achieved the highest scores (mean \pm SD $71.0 \pm 27.6 \%$ and $64.4 \pm 37.5 \%$ respectively), while 'editorial independence' showed the lowest mean score 
$(9.2 \pm 13.3 \%)$. While few of the bereavement care practice guidelines met the AGREE II quality standards related to their development process, neither the quality of the content of each guideline or the in-context application was assessed by the AGREE II instrument. Ongoing development of practice guidelines may benefit from consideration and application of the framework outlined in the AGREE II or similar appraisal instrument.

\section{Keywords}

bereavement, grief, bereavement care, clinical practice guidelines, systematic review, agree II instrument, evaluation

\section{Introduction}

Grief and bereavement are natural and universal human experiences, which occur before, during and after a significant person in someone's life dies ${ }^{1}$. However, just as the circumstances surrounding every death are varied, each individual can experience bereavement in different ways, which may reflect the nature of the death, their relationships, their social supports and cultural context ${ }^{2}$. Most people find ways to deal with grief and bereavement over time, with the needs of bereaved individuals largely met through obtaining support within their existing networks such as family and friends. However, a proportion of bereaved individuals experience complicated grief, or Prolonged Grief Disorder, which can interfere with normal daily functions ${ }^{3}$ and is recognized as an intense psychological illness that requires professional interventions ${ }^{4}$. There is no one size fits all approach to bereavement care, and care is usually provided through both informal and formal approaches that may be delivered by one or an array of health or community care practitioners ${ }^{5}$. It has long been recognized that the provision of bereavement care is multi-faceted, often involving families, friends, health care professionals, bereavement support groups and the wider community ${ }^{6}$. 
In the area of health and medicine, practice guidelines are decision-making aids that are developed for application when caring for an individual in a preventive, diagnostic, therapeutic and/or palliative setting ${ }^{7}$. Ideally practice guidelines are systematically developed using an evidence-based approach, are person-centered and implemented to ensure that ethical standards are upheld in clinical settings, in order to protect people from harm and improve health outcomes $^{8}$. Further, they may assist with health policy formation at the system level and guide service improvements, or be used to assess the quality of existing services by establishing a minimum standard for an individual practitioner or service ${ }^{5}$. Bereavement care practice guidelines can therefore be interpreted as clinical tools or statements of principles that influence the development and provision of bereavement care ${ }^{5}$. In the context of the multi-faceted nature of bereavement care, guidelines can also provide a basis for uniting and coordinating a range of bereavement care providers and facilitating a variety of services to achieve and maintain consistent service provision ${ }^{5}$.

Although bereavement care practice guidelines are developed to support the delivery of high-quality care to bereaved individuals, no standardised process has been adopted for either the development, or evaluation of existing tools. Guidelines developed without rigorous criteria can undermine the credibility of the authoring organization and may "be more harmful than beneficial” ${ }^{9 p g 124}$. A further complication is that the bereavement care sector comprises a broad range of individuals, organisations, and services which may require context specific practice guidelines. Consequently, bereavement care practice guidelines have been, and need to be, developed in consideration of the target audience and context in mind. The differences in available practice guidelines may therefore reflect the prominent values and the evidencebase relevant to their authors and apply specifically to the setting for which they were developed ${ }^{7}$. Regardless of such individuality or the setting for which they were developed, it is important to identify high quality, trustworthy practice guidelines to confidently recommend 
their application for improving health care quality and health outcomes in the bereavement care sector ${ }^{8}$. Since the quality of the development of these guidelines may vary considerably, a strategy is needed to help choose which guidelines should be selected for adoption and use. One way to determine the quality of bereavement care practice guidelines is to appraise the processes used in their development.

The Appraisal of Guidelines for Research and Evaluation II (AGREE II) instrument is an internationally recognized tool reported to be valid and reliable ${ }^{10}$. There are many practice guideline appraisal tools available, which differ according the type of quality appraisal outcome required. However, the AGREE II is among the most comprehensive and widely utilized guideline appraisal tools ${ }^{11}$, with at least 10 other guideline appraisal tools reporting that the AGREE II instrument informed their development ${ }^{11}$. Quality appraisal of practice guidelines in other health-related fields reveals that guidelines often vary widely in quality ${ }^{10}$, which may reflect poor development processes. However, systematic identification and quality appraisal of bereavement care practice guidelines has not yet been attempted, despite the positive implications the findings may have for bereavement care practice. The AGREE II provides important information on whether a guideline is a reliable basis for application in clinical practice ${ }^{12}$.

Through the 'Better Access to Palliative Care Project’ in Tasmania, Australia a regional bereavement care network was established ${ }^{13}$. The network consisted of a broad range of bereavement care providers who identified that guidelines or standards for the delivery of quality care would be useful to their practice. The aim of this review was therefore to identify and evaluate the quality of existing bereavement care practice guidelines to inform this process. A systematic review was conducted to: (1) generate a list of current bereavement care practice guidelines; and (2) to evaluate the quality of their development using the AGREE II. 


\section{Methods}

\section{Literature Search}

The research question guiding the literature search was "What is the quality of current bereavement care practice guidelines?”. Whilst the term 'practice guidelines' is used throughout this review, the term was regarded as synonymous with the following: clinical guidelines, standards, charters, guidelines, or principles, with each phrase changing depending on the setting.

A detailed literature search was conducted in October 2017 to identify published (e.g. academic and professional journals) and non-published or grey literature (e.g. government reports, websites). This included the following steps:

- A search in academic databases MEDLINE Complete, CINAHL Complete, Health Source: Nursing/Academic Edition, Psychology and Behavioral Sciences Collection using the following key word search terms: (bereavement or grief) AND (clinical practice guideline OR value OR principle OR standard of care OR charter OR guideline OR quality assurance OR professional practice OR practice guideline);

- A search (using the same key word search terms) via an internet search engine (www.google.com) and a dedicated search in relevant websites;

- A manual search of the reference lists and bibliographies of articles retrieved to locate additional literature.

Identified literature were exported into a dedicated Endnote Library established for this study (Endnote version X8, Thomson Reuters, 2017). The document titles, abstracts and full texts were screened against the inclusion/exclusion criteria. Articles were considered for inclusion if the full text was available and written in English (due to a lack of translational resources). The key inclusion criteria for articles was any information relating to the development, application or evaluation of bereavement care practice guidelines. Articles were 
excluded if they described palliative care guidelines that contained only a subsection or statement on bereavement care, due to the lack of detail on the provision of bereavement care specifically.

\section{[INSERT FIGURE 1 NEAR HERE]}

The search (overview in Figure 1) identified 2,759 articles, from which 881 duplicates were removed. Screening of titles identified 69 articles for potential inclusion relating to the development or application of bereavement care practice guidelines in any setting. After full text retrieval and evaluation against the inclusion/exclusion criteria, a total of 19 articles were included in the final review. This included 16 practice guidelines found within the grey literature and 3 scholarly articles. The purpose and setting of each bereavement care guideline were identified and the values and principles of each guideline extracted and compared. Relevant data is presented in Table 2 with an accompanying narrative synthesis.

\section{Quality Appraisal using AGREE II instrument}

\section{[INSERT TABLE 1 NEAR HERE]}

Systematic evaluation of the quality of development of each bereavement care practice guideline was made using the AGREE II instrument (Table 1) ${ }^{10}$. The AGREE II instrument was selected as an appropriate tool for appraising the development of bereavement care practice guidelines given that it has been applied in similar palliative and health care-related fields ${ }^{14-17}$. This evaluation instrument focusses on the process used to develop the guideline rather than the specific content within each guideline ${ }^{16}$. The AGREE II instrument consists of 6 domains: Scope and Purpose (items 1-3); Stakeholder Involvement (items 4-6); Rigor of Development (items 7-14); Clarity of Presentation (items 15-17); Applicability (items 18-21); and Editorial Independence (items 22-23). An additional two-question 'overall guideline assessment' asks 
the reviewer to judge the overall quality and indicate whether they would recommend the guideline for use.

After completing the AGREE II online training tools and studying the user manual ${ }^{18,19}$, two reviewers scored each guideline independently. Both reviewers rated all 23 items (Table 1) for each guideline according to a 7-point scale ranging from 1 (strongly disagree, indicating no relevant information is provided) to 7 (strongly agree, indicating the quality of reporting is exceptional). Both reviewers also completed the additional 'overall guideline assessment', rating the overall quality of the guidelines with a score between one and seven, and indicated if they would recommend the guideline for use based on the development process evaluation by responding 'yes', ‘yes with modifications' or 'no'.

Given the subjective determination used by the AGREE II tool to identify if the guideline should be recommended for use, the present study chose to adopt further calculations in an effort to provide further rigor to the assessment process. These additional calculations mirror the steps taken in other studies that have similarly used the AGREE II tool to appraise the guideline development process ${ }^{10,20}$. Item scores from each reviewer were entered independently and collated in a Microsoft Excel 2017 spreadsheet. The final scores for each domain were calculated by summing the item scores within each domain from both reviewers and scaling the total as a percentage of the maximum possible score for that domain ${ }^{10,20}$. Domain scores were categorized as good ( $\geq 80 \%$ ), acceptable (60-79\%), low (40-59\%) or very low $(<40 \%)^{10}$. The mean (and standard deviation) was calculated for a 'total guideline score' for every practice guideline in addition to the 'total domain score' for each domain, to highlight where individual guidelines performed well overall, and to identify any consistency or variability among domains for guidelines ${ }^{20}$ The overall quality of each guideline was evaluated using a threshold of $60 \%$ for the final score of each domain ${ }^{20}$. High quality was defined when 5 or more domains scored $>60 \%$, average quality when 3 or 4 domains scored $>60 \%$ and low- 
quality when $\leq 2$ domains scored $>60 \%{ }^{20}$. Finally, inter-rater reliability (agreement between the two reviewers' item scores) was calculated using the (Two-Way Random) intraclass correlation coefficient (ICC) with SPSS software (SPSS version 23.0; IBM Corporation, Somers, NY, USA). Agreement was described as follows: $<0.20$ poor; $0.21-0.40$ fair; 0.410.60 moderate; $0.61-0.80$ good; $0.81-1.00$ very good ${ }^{20}$.

\section{Results}

\section{[INSERT TABLE 2 NEAR HERE]}

A total of 19 articles and guidelines were included in this review, comprising three articles sourced from academic database search ${ }^{21-23}$ and sixteen practice guidelines retrieved from the grey literature (Table 2). ${ }^{24-39}$

\section{Academic database search}

Three articles were identified that discussed the development, application or evaluation of bereavement care practice guidelines. One journal article ${ }^{21}$ detailed the methods for the development of national level bereavement care guidelines. The authors described the consultative approach used in development and the framework used to structure the practice guidelines. The associated guideline document ${ }^{31}$ was located in the grey literature search and reviewed. The two remaining articles ${ }^{22,23}$ were editorials that promoted and briefly described the development of bereavement care guidelines. These were later reviewed after retrieval through the grey literature search ${ }^{24,34}$. Therefore, the search of academic electronic databases did not yield any bereavement care practice guidelines that were not identified in the grey literature search. 
Sixteen guidelines were identified from the grey literature search. The practice guidelines were from six Western countries (Table 2) including the UK $(n=6)$, Australia $(n=4)$, Ireland $(n=2)$, the USA $(n=2)$, Canada $(n=1)$, and New Zealand $(n=1)$. The purpose and scope of the guidelines varied depending on their intended audience, with eight organizational 26,27,29,32,35,37${ }^{39}$, one regional ${ }^{30}$, and seven national level ${ }^{24,25,28,31,33,34,36}$ guidelines identified (Table 2). The national-level guidelines ${ }^{24,25,28,31,33,34,36}$ were comprehensive documents that aimed to provide broad guidance for improving service provision ${ }^{25}$, including resource allocation ${ }^{24}$ and improving access to services. An additional aim was to maximize coordination between service providers ${ }^{31}$ and improve training and support for those delivering care ${ }^{25}$. The regional level guideline ${ }^{30}$ was written for a network of several organisations in one geographical region and aimed to unite service providers. The organizational level guidelines ${ }^{26,27,29,32,35,37-39}$ included organizations such as hospitals, bereavement support organisations and charities. These guidelines were found to include aspirational and unifying statements regarding how such organisations would provide high-quality, consistent bereavement care ${ }^{35}$, and provided guidance directed at staff roles and operational policies and procedures to manage the delivery of bereavement care ${ }^{38}$.

Similar core values and principles were identified across the bereavement care practice guidelines. Common values included working with respect and integrity ${ }^{24,30,35}$, and providing dignity to bereaved individuals ${ }^{25,26}$. Common principles of bereavement care included striving to provide high-quality ${ }^{24,39}$, collaborative ${ }^{24,28,39}$, accessible ${ }^{31,37}$ and adequately resourced care 39. Additionally, safety for staff ${ }^{26,31}$, ethical care provision ${ }^{24,29}$, and ongoing monitoring and evaluation of service delivery ${ }^{24,25}$ were identified as priorities.

\section{Quality Appraisal}


The results of the quality appraisal using the AGREE II instrument for each guideline are shown in Table 3, including a 'total guideline score' for every practice guideline and the 'total domain score', in addition to both individual reviewer's recommendations for use for each of the 16 guidelines. There was complete agreement between the two reviewers about recommending the guidelines for use (Table 3). Both reviewers recommended three guidelines 26,29,31 as suitable for use based on their development process. The reviewers recommended a further five guidelines ${ }^{25,28,30,32,39}$ were recommended for use following some modifications relating to the domains in which they achieved low or very low scores. The remaining eight guidelines ${ }^{24,27,33-38}$ were not recommended for use by reviewers based on their development process.

\section{[INSERT TABLE 3 NEAR HERE]}

According to the additional calculations conducted as part of this study, only one of the 16 guidelines reached a high level of overall quality ${ }^{31}$, having at least five domain scores higher than $60 \%$. This guideline achieved the highest total guideline score (mean \pm standard deviation (SD) 76.9 $\pm 29.0 \%)$. A further four guidelines reached an average level of quality ${ }^{25,26,29,30}$, with either three or four domains scoring $>60 \%$. The total guideline score means for these average quality guidelines ranged from $46.2+29.7 \%$ to $66.6 \pm 35.8 \%$. The remaining eleven guidelines 24,27,28,32-39 were found to be of low quality, with $\leq 2$ domain scores higher than $60 \%$ (total guideline score mean \pm SD ranging from $10.9 \pm 18.4 \%$ to $54.334 .8 \%$ ).

Large variability was evident across domain scores for each guideline, with scores ranging between $0 \%$ and $100 \%$. The highest variability amongst individual domain scores was $40.8 \%{ }^{28}$, and the lowest variability was $4.5 \%{ }^{36}$. When comparing the scores of each domain 
across guidelines, domain 1 (Scope and Purpose) achieved the second-highest total domain score (67.4+37.5\%). Five guidelines achieved the highest possible score of $100.0 \%{ }^{28,30,31,38,39}$ on this domain, while four guidelines scored very low ${ }^{33-36}$. The total domain 2 score mean (Stakeholder Involvement) was low $(42.1 \pm 25.2 \%)$, with guidelines ranged from $2.8 \%{ }^{33}$ to $91.7 \%$ 31. Domain 3 (Rigor of Development) had the second-lowest total domain score mean (20.6+26.4\%). Hudson et al., ${ }^{31}$ achieved the highest score of $82.3 \%$ (good) for domain 3, with four guidelines ${ }^{33-35,37}$ awarded the lowest possible score of $0 \%$. Domain 4 (Clarity of Presentation) achieved the highest score with total domain score mean \pm SD of $71.0 \pm 27.6 \%$, but a range from ${ }^{28-32} 16.7 \%$ (very low) ${ }^{36}$ to $100 \%$ (good) ${ }^{28-32}$. The total score mean of domain 5 (Applicability) was 32.3\% $\pm 23.7 \%$, ranging from $70.8 \%{ }^{30}$ (acceptable) to $0 \%$ (very low) ) $^{34,35}$. Domain 6 (Editorial Independence) was found to have the lowest total domain score mean of $9.2 \pm 13.3 \%$., and all 16 guidelines had very low scores, with 10 guidelines failing to achieve any score $(0 \%)$ on this domain $26-28,30,33-35,37-39$. Inter-rater reliability analysis revealed very good agreement between the two reviewers for all guidelines (ICC range 0.895-0.990) (Table 3

Comparison of the assessment of the overall quality of the guidelines made using the AGREE II tool against the additional calculations of quality showed that most guidelines were scored similarly. For example, most "Low" scoring guidelines were not recommended for used $^{27,33-38}$, however some would be recommended after modification ${ }^{25,28,32,39}$. Likewise, three “Average” and "High" scored guidelines were recommended for use without modification $^{26,29,31}$, whilst it is suggested two others require modification ${ }^{25,30}$ before application.

\section{Discussion}

To the best of our knowledge, this review is the first systematic identification and quality appraisal of bereavement care practice guideline development. Overall, there is little literature 
from academic databases regarding the development or application of bereavement care practice guidelines, with the all bereavement care practice guidelines being identified from the grey literature. Other evaluations of clinical practice guidelines have also highlighted the importance of a comprehensive grey literature search strategy to source guidelines in multidisciplinary fields ${ }^{16}$. The practice guidelines identified specifically for bereavement care were all developed in Western countries. Each had a slightly different scope and target audience reflecting the wide breadth of people and organisations involved in the provision of bereavement care. However, common values and principles were evident across the guidelines, highlighting the shared aspirations of bereavement care providers to improve bereavement care services and to enhance outcomes for all bereaved individuals. A strong consensus regarding the shared values and principles across the guidelines reviewed clearly support the intent to establish a consistent set of standards in the delivery of safe, ethical and appropriate delivery of bereavement care. In the future, these shared values and principles may be used to build consensus between bereavement care providers at an international level.

Despite consistency in shared values and principles across the bereavement care practice guidelines reviewed, few met the quality standards for their development process as described by the AGREE II instrument. Our review identified a large variation in quality of guidelines across all six domains, which is consistent with other clinical practice guideline reviews when guidelines are sourced from predominantly from grey literature sources 16,40 . Only one identified bereavement care practice guideline showed high quality overall, and only three were recommended for use (according to the AGREE II instrument) without modification. A further five guidelines were reviewed and assessed as useful with modification, which is a practical finding given that partial revision or updating of guidelines may be more feasible than developing new guidelines ${ }^{41}$. Additionally, these suggestions are subjective recommendations and based on an assessment of the processes used to develop the guidelines, they may not 
accurately reflect the suitability of the content presented within each guideline, which may still be suitable for the context for which it was developed.

Despite the overall quality of guidelines being quite poor, high scores in the domains relating to the 'clarity of presentation' and 'scope and purpose' were consistently observed, indicating that most guidelines had a specific and targeted purpose and were clearly written. Brouwers et al. ${ }^{42}$ identified that the high scores for the domain 'clarity of presentation' is supported by guidelines giving clear summaries of unambiguous recommendations and offering several clearly described management options. The high scores in these domains supports the usefulness and practical application of the guidelines and is a strength of current bereavement care practice guidelines.

In line with other reviews of clinical practice guidelines ${ }^{40}$, a large variability was evident across domain scores in many guidelines included this review, indicating they scored well in some domains, but poorly in others. For example, one overall high-scoring bereavement care practice guideline ${ }^{31}$ achieved a 'very low' score in one domain (editorial independence). Editorial independence has historically been the weakest scoring domain in guideline development ${ }^{43}$, yet could be improved simply by the authors clearly stating independence from their funding body and declaring any competing interests. This finding is in accordance with a recent review which determined when applying the AGREE II tool to evaluate practice guidelines, the items related to editorial independence of authors appear to have the greatest influence on the overall assessment of guideline quality and recommendations for use ${ }^{12}$. Another review of medicine-related clinical practice guidelines identified that information on conflicts of interest was provided in fewer than half of the guidelines identified ${ }^{44}$. While a high level of objectivity and declaration of conflicts of interest in bereavement care practice guidelines may not be a priority in all settings, guideline 
users may need to discern whether this affects the trustworthiness of the guideline for their intended use.

Other guidelines were found to have scored $24,33-36$ 'low' or 'very low' across all domains, suggesting that more generalized improvement is required across a variety of domains to improve their overall AGREE II score, and hence allow their application to bereavement care service provision. Interestingly, the guidelines which received the lowest quality appraisal ${ }^{35,36}$ were generally from smaller networks or organisations, whereas wellsupported and funded national level guidelines ${ }^{29,31}$ scored more highly. This may reflect differences in the level of funding, time and academic resources available within organisations to undertake the rigorous development of bereavement care guidelines. For example, one bereavement care charter for a charity ${ }^{35}$ was reportedly developed based on professional opinion and anecdotal experience: “They [children and their families] have told us what they need to rebuild their lives and face the future with hope” 35 (pg 1). Conversely, another practice guideline was thoroughly researched and evidence-based: “[These standards were developed using a] review of international evidence on the impact of bereavement and bereavement interventions” ${ }^{31}$ (pg. 6). The bereavement care practice guidelines for more informal care provision may score lower using the AGREE II quality appraisal instrument, despite sharing the common values and principles with a higher scoring document. It is important to note that while several of the guidelines developed for smaller networks and organisations scored poorly, their merit should not be questioned out of context, as the guideline may well be appropriate for its intended purpose. Further evaluation of the quality of the content presented in each guideline is needed to understand further how the currently available bereavement care guidelines can support and guide best practice in this area. While the AGREE II instrument is widely accepted as a robust instrument, it may have limitations 
for the quality appraisal of practice guidelines in the diverse arena of bereavement care. This is highlighted in our analysis, with two different methods of assessment of the overall quality of each guideline showing mixed results for some guidelines (Table 3). Therefore, when selecting and implementing bereavement care guidelines, quality appraisal tools can only go so far, and individuals need to consider the appropriateness of each guideline in the context of their intended purpose.

Understanding and utilizing the quality appraisal outcomes outlined in the AGREE II or similar appraisal instrument may benefit the ongoing development of bereavement care practice guidelines. However, when developing guidelines, it is important to acknowledge the range of care providers in the field bereavement care, and that bereavement care practice guidelines need not be overly prescriptive. Rather they should clarify the goals and principles underlying the provision of good bereavement care. The diversity between formal and informal bereavement care providers means it is unlikely that all individuals working in this area possess the time, skills or resources to be able to search for and evaluate best-practice evidence. Therefore, strategies are required to improve access to reliable up-to-date evidence across a simple and informal platform. An example of this is the free and trustworthy palliative care and bereavement specific search tool called CareSearch, which has recently been developed as a service to connect practitioners to global best practice evidence ${ }^{45}$.

It has been suggested that there may be a perceived (or actual) disconnect between researchers and practitioners in the field of bereavement care, which may be a factor that limits both the development and application of bereavement care practice guidelines. A lack of practical implementation for guidelines in other health-care fields has been reported ${ }^{16,46}$ indicating the extent of this issue. Successful implementation of guidelines is dependent on a substantial amount of time, money and resources. There is also limited decisive guidance on how guidelines can be successfully implemented ${ }^{46}$, which may be limiting the effectiveness 
of guidelines for patient health outcomes. It has been argued that many practitioners believe that scientific research holds little relevance for their work, and conversely, some researchers consider clinical practice has little applicability to the scientific study of bereavement ${ }^{47}$. Nevertheless, a growing body of evidence suggests that clinicians and researchers can and should inform bereavement practices, including the development and implementation of practice guidelines ${ }^{47}$ through improving communication channels and knowledge exchange across the sector. Utilizing the existing quality appraisal frameworks, such as the considerations outlined in the AGREE II instrument, may support the development of robust guidelines for bereavement care.

Regardless of how well bereavement care practice guidelines may be written, it is likely that compromises will be made between the practice ideal and pragmatism when being implemented $^{48}$. Recent surveys paint a sobering picture of the extent to which current bereavement care practice guidelines are implemented in palliative care services. One survey that evaluated the alignment between bereavement care provided by palliative care services and existing practice guidelines in Australia ${ }^{49}$ found a disconnect between bereavement support provided by these services and the established practice guidelines and assessment tools. Less than $25 \%$ of palliative care services who responded to the survey reported complying with a practice guideline which related to a care provider conducting a follow up assessment with bereaved clients. Similarly, a large survey of bereavement support practices ${ }^{50}$ across 370 palliative care services reported that bereavement care did not appear to be sufficiently integrated into palliative care practice. It was reported that only 33\% of services based their practice on formal guidelines or policies. The overall low quality of guidelines identified in this review may be a factor contributing to their lack of application in clinical practice. This highlights the importance of the recommendations made in this review to improve the process used to develop bereavement care practice guidelines. Additionally, greater consideration must 
be given to the opinions and stand-points of managers and funding agencies throughout the development, subsequent implementation and evaluation of practice guidelines ${ }^{47}$ to support their adoption in clinical practice.

Whilst this review has provided useful information on bereavement care guidelines, it is not without limitation. The review of written bereavement care practice guidelines in this study may not fully capture the implementation of bereavement care practice guidelines when delivering care. For example, there may be word or page limits on published guidelines that do not reflect the level of preparation in the development process. Alternatively, bereavement care practitioners may have limited need for understanding how guidelines were developed and may prioritize the suitability and usefulness of the guidelines to their practice. While the development process is an important consideration, the methodological rigor and quality of the clinical content within a clinical practice guideline are not necessarily correlated ${ }^{11}$. Therefore, when considering the quality of bereavement care practice guidelines, users of these tools may find it useful to couple this with a content appraisal to ensure a tool is contextually appropriate for their purpose. Additionally, despite our best efforts and a comprehensive search strategy, it is possible that not all bereavement care practice guidelines were identified. This may include bereavement care practice guidelines not written in English, which may have limited the scope of our evaluation to guidelines from Western countries. Across the world, there are culturally specific customs and beliefs surrounding death, and in the West, there is a cultural drift away from traditional ways of mourning ${ }^{51}$. Therefore, generalizing the findings of this review may be ethnocentric, and local cultural values must be considered when providing bereavement care. An additional limitation is the exclusion of palliative care practice guidelines that did not focus specifically on bereavement care. As palliative care providers often integrate bereavement care into their practice this could have excluded relevant information. Despite these limitations, this 
review is significant as the first systematic review of available bereavement care guidelines, coupled with an evaluation of the quality of their development process.

In conclusion, this review is the first systematic identification and quality appraisal of bereavement care practice guidelines based on the guideline development process using the AGREE II instrument. This review identified sixteen bereavement care practice guidelines, which were from grey literature sources, that had been developed for a variety of purposes, but shared similar values and principles relating to the provision of consistent, safe, ethical and appropriate bereavement care. One guideline had overall high quality and three could be recommended for use without modification, indicating few of the bereavement care practice guidelines identified met the quality standards related to the process used to develop the article. However, as the quality of the guideline content was not appraised this outcome should be interpreted cautiously, as the content of each guideline may well be appropriate for its intended purpose. The use of the AGREE II or similar appraisal instrument has the potential to help an individual discern whether an existing guideline is suitable for their scope and purpose. Additionally, appraisal instrument frameworks may be useful to improve the ongoing development of practice guidelines and subsequently contribute to improvements in care delivery. Further research on the quality appraisal of the content of bereavement care guidelines is warranted to complement our appraisal of the development processes.

\section{References}

1. Ayers T, Balk D, Bolle J, et al. Report on bereavement and grief research. Death Studies. 2004;28(6):491-575.

2. Christian KM, Aoun SM, Breen LJ. How religious and spiritual beliefs explain prolonged grief disorder symptoms. Death Studies. 2019;43(5):316-323.

3. Bryant RA. Current knowledge about prolonged grief disorder. Grief Matters: The Australian Journal of Grief and Bereavement. 2018(1):21.

4. Johannsen M DM, Zachariae R, Lundorff M, Farver-Vestergaard I, O'Connor M. Psychological interventions for grief in adults: A systematic review and meta-analysis of randomized controlled trials. Journal of Affective Disorders. 2019;253:69-86. 
5. Keegan O. Standards for bereavement care Morrison Chambers, 32 Nassau Street, Dublin 2: Irish Hospice Foundation 2002.

6. Rumbold B, Aoun S. An assets-based approach to bereavement care. Bereavement Care. 2015;34(3):99-102.

7. McSweeney M, Spies M, Cann CJ. Finding and evaluating clinical practice guidelines. Nurse Practitioner. 2001;26(9):30-39.

8. Graham R MM, Miller Wolman D, Greenfield S, Steinberg E, eds. Clinical practice guidelines we can trust. In: National Academies Press; 2011.

9. Jin Y, Wang Y, Zhang Y, et al. Nursing Practice Guidelines in China do Need Reform: A Critical Appraisal Using the AGREE II Instrument. Worldviews on Evidence-Based Nursing. 2016;13(2):124-138.

10. Brouwers MC, Kho ME, Browman GP, et al. AGREE II: advancing guideline development, reporting and evaluation in health care. Canadian Medical Association Journal. 2010;182(18):E839-E842.

11. Siering U, Eikermann M, Hausner E, Hoffmann-Eßer W, Neugebauer EA. Appraisal Tools for Clinical Practice Guidelines: A Systematic Review. PLOS ONE. 2013;8(12):e82915.

12. Hoffmann-Eßer W, Siering U, Neugebauer EAM, et al. Guideline appraisal with AGREE II: online survey of the potential influence of AGREE II items on overall assessment of guideline quality and recommendation for use. BMC Health Services Research. 2018;18:1-1.

13. Barnett TaB, H and Marsh, P and Kent, K and Ball, M. . Tasmanian bereavement care network and initiatives project: final report. Centre for Rural Health, University of Tasmania, Australia 2017.

14. Abarshi E, Rietjens J, Robijn L, et al. International variations in clinical practice guidelines for palliative sedation: a systematic review. BMJ Supportive \& Palliative Care. 2017;7(3):223-229.

15. Birken SA, Ellis SD, Walker JS, et al. Guidelines for the use of survivorship care plans:a systematic quality appraisal using the AGREE II instrument. Implementation Science. 2015;10(1):1-9.

16. Bush SH, Marchington KL, Agar M, Davis DHJ, Sikora L, Tsang TWY. Quality of clinical practice guidelines in delirium: a systematic appraisal. BMJ Open. 2017;7(3).

17. Durepos P, Wickson-Griffiths A, Hazzan AA, et al. Assessing Palliative Care Content in Dementia Care Guidelines: A Systematic Review. Journal of Pain \& Symptom Management. 2017;53(4):804-813.

18. Website. AE. http://www.agreetrust.org/resource-centre/training/.

19. Brouwers MC, Kho ME, Browman GP, et al. Development of the AGREE II, part 2: assessment of validity of items and tools to support application. CMAJ : Canadian Medical Association Journal. 2010;182(10):E472-478.

20. Messina C, Bignotti B, Bazzocchi A, et al. A critical appraisal of the quality of adult dual-energy X-ray absorptiometry guidelines in osteoporosis using the AGREE II tool: An EuroAIM initiative. Insights into Imaging. 2017;8(3):311-317.

21. Hudson P, Remedios C, Zordan R, et al. Guidelines for the Psychosocial and Bereavement Support of Family Caregivers of Palliative Care Patients. Journal of Palliative Medicine. 2012;15(6):696-702.

22. Kerslake D, Chaplin D, Hartley J, Wadey A. New Bereavement Care Service Standards. Bereavement Care. 2014;33(1):28-32.

23. Jones R. Pregnancy loss and the death of a baby: guidelines for professionals. Infant. 2016;12(6):198-199. 
24. Cruse Bereavement Care and the Bereavement Services Association (BSA). Bereavement care service standards United Kingdom: Cruse Bereavement Care and the Bereavement Services Association(BSA);2013.

25. Scottish Government Health Directorate. Shaping Bereavement Care: Consultation On A Framework For Action For Bereavement Care. Scotland: Scottish Government Health Directorate;2010.

26. The MidCentral District Health Board (MDHB) Palliative Care District Group. Palliative Care Bearevament Support Guidelines. New Zealand: The MidCentral District Health Board (MDHB) Palliative Care District Group.;2015.

27. American Association of Suicidology. Recommended guiding principles for effective suicide bereavement support groups. Washington, DC: American Association of Suicidology;2012.

28. Health Service Executive. National Standards for Bereavement Care following Pregnancy Loss and Perinatal Death. Ireland: Health Service Executive;2016.

29. Hall C, Hudson, P., Boughey, A. . Bereavement support standards for specialist palliative care services. Melbourne Australia, 2012.

30. Anglia Cancer Network. Policy - Bereavement Care United Kingdom: Anglia Cancer Network 2011.

31. Hudson P, Remedios, C., Zordan, R.,Thomas, K.,Clifton, D., Rewdson , M., Hall, C., Trauer, T., Bolleter, A., and Clarke, D. Clinical Practice Guidelines for the Psychosocial and Bereavement Support of Family Caregivers of Palliative Care Patients. Melbourne, Australia: Centre for Palliative Care, St Vincent's Hospital;2010.

32. Lifeline Australia And Australian Government Department Of Health And Ageing Towards Good PracTice: Standards and Guidelines for Suicide Bereavement Support Groups. Australia: Lifeline australia and australian Government department of Health and ageing;2009.

33. British Bnking Association;. Bereavement Principles United Kingdom: British Banking Association;2016

34. SANDS. SANDS Principles Of Bereavement Care. 2016; https://www.uksands.org/professionals/principles-bereavement-care/sands-principles-bereavementcare.; ND

35. Winston’s Wish. Charter for bereaved children. Winston’s Wish 2017 http://www.winstonswish.co.uk/supporting-you/supporting-a-bereaved-child/, 2017.

36. The Irish Childhood Bereavement Network (ICBN). Childhood Bereavement Principles. n.d.; http://www.childhoodbereavement.ie/about-us/vision-mission-andprinciples/\#.WcCkTY9OISs.

37. BC's Children's \& Women's Health Centre and Canuck Place Children's Hospice. Guidelines for Loss Support of Dying Children \& Their Families. Canada; ND.

38. SANE. SANE Bereavement Guideline. Australia: SANE;n.d.

39. The National Action Alliance for Suicide Prevention. Responding to grief, trauma and distress after a suicide: U.S. National Guidelines. U.S.A: The National Action Alliance for Suicide Prevention;2015.

40. Burda BU, Norris SL, Holmer HK, Ogden LA, Smith MEB. Quality varies across clinical practice guidelines for mammography screening in women aged 40-49 years as assessed by AGREE and AMSTAR instruments. Journal of clinical epidemiology. 2011;64(9):968-976.

41. Becker M, Neugebauer EA, Eikermann M. Partial updating of clinical practice guidelines often makes more sense than full updating: a systematic review on methods 
and the development of an updating procedure. Journal Of Clinical Epidemiology. 2014;67(1):33-45.

42. Brouwers MC, Kho ME, Browman GP, et al. Development of the AGREE II, part 1: performance, usefulness and areas for improvement. Canadian Medical Association Journal. 2010;182(10):1045-1052.

43. Armstrong JJ, Goldfarb AM, Instrum RS, MacDermid JC. Improvement evident but still necessary in clinical practice guideline quality: a systematic review. Journal of Clinical Epidemiology. 2017;81:13-21.

44. Kung J, Miller RR, Mackowiak PA. Failure of Clinical Practice Guidelines to Meet Institute of Medicine Standards: Two More Decades of Little, If Any, ProgressFailure of Guidelines to Meet IOM Standards. JAMA Internal Medicine. 2012;172(21):16281633.

45. Tieman J, Hayman S, Hall C. Find me the evidence: connecting the practitioner with the evidence on bereavement care. Death Studies. 2015;39(1-5):255-262.

46. Kredo T, Bernhardsson S, Machingaidze S, et al. Guide to clinical practice guidelines: the current state of play. International journal for quality in health care. 2016;28(1):122-128.

47. Sandler I, Balk D, Jordan J, Kennedy C, Nadeau J, Shapiro E. Bridging the gap between research and practice in bereavement: report from the Center for the Advancement of Health. Death Studies. 2005;29(2):93-122.

48. Richter Sundberg L, Garvare R, Nyström ME. Reaching beyond the review of research evidence: a qualitative study of decision making during the development of clinical practice guidelines for disease prevention in healthcare. BMC Health Services Research. 2017;17(1):344.

49. Aoun SM, Rumbold B, Howting D, Bolleter A, Breen LJ. Bereavement support for family caregivers: The gap between guidelines and practice in palliative care. Plos One. 2017;12(10):e0184750-e0184750.

50. Guldin M MI, KeeganO, Monroe B, Lacasta-Reverte M, Benkel I. Bereavement services in palliative care in Europe: A survey study by the European Association for Palliative Care bereavement taskforce. European journal of Palliative Care. 2015;22(4):185-189.

51. Parkes CM, Laungani P, Young W. Death and Bereavement Across Cultures: Second edition. Taylor \& Francis; 2015.

\section{Acknowledgements}

The authors would like to acknowledge that a preliminary scoping review of this topic was undertaken before this systematic search and quality appraisal, and this scoping was published in print and online as part of a contract report: Barnett T, Bridgman H, Marsh P, Kent K, Ball M, 'Tasmanian bereavement care network and initiatives project: final report', Centre for Rural Health, University of Tasmania, Australia (2017). Available at: http://bcntasmania.org.au/index.php/11-news/36-bcn-final-report 


\section{Funding}

This review was conducted as part of a larger project, funded by the Tasmanian Department of Health and Human Services through the Better Access to Palliative Care Initiative. The motivation for undertaking this review was to develop Bereavement Care Standards for Tasmania, Australia to accompany the establishment of a state-wide Bereavement Care Network (www.bcntasmania.org.au)

\section{Declaration of conflict of interest}

All authors have no conflict of interest to declare.

\section{Authorship Declaration}

KK, TB, PM, MB were responsible for the project conceptualisation and refining research ideas. KK was responsible for the literature search, instrument selection, collection and preparation of data. KK and BJ appraised the quality of the practice guidelines using the AGREE II instrument and drafted the first copy of the manuscript. All authors contributed to the editing and subsequent drafts of the manuscript and approved this manuscript for publication. 
Figures Legend: Figure 1 Overview of the search strategy and results

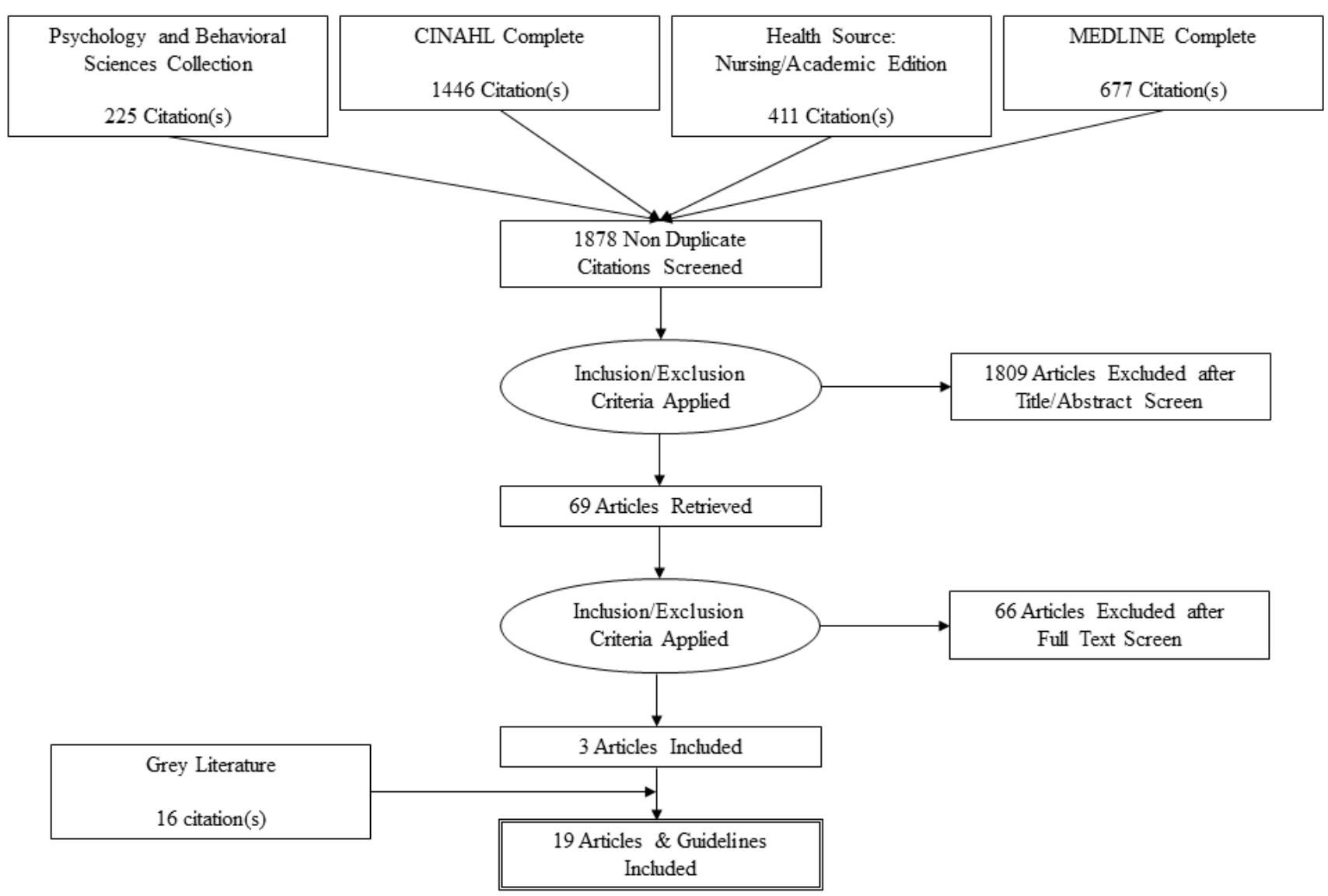

Figure 2 Overview of the search strategy and results 
Tables

Table 1 Summary of AGREE II structure and detailed list of items within each scoring domain

\begin{tabular}{|c|c|c|}
\hline \multirow{4}{*}{$\begin{array}{l}\text { Domain name } \\
\text { 1. Scope and Purpose }\end{array}$} & Item & Feature to be evaluated \\
\hline & 1 & $\begin{array}{l}\text { The overall objective(s) of the guideline is (are) } \\
\text { specifically described }\end{array}$ \\
\hline & 2 & $\begin{array}{l}\text { The health question(s) covered by the guideline is (are) } \\
\text { specifically described }\end{array}$ \\
\hline & 3 & $\begin{array}{l}\text { The population to whom the guideline is meant to apply is } \\
\text { specifically described }\end{array}$ \\
\hline \multirow[t]{3}{*}{$\begin{array}{l}\text { 2. Stakeholder } \\
\text { Involvement }\end{array}$} & 4 & $\begin{array}{l}\text { The guideline development group includes individuals } \\
\text { from all the relevant professional groups }\end{array}$ \\
\hline & 5 & $\begin{array}{l}\text { The views and preferences of the target population } \\
\text { (patients, public, etc.) have been sought }\end{array}$ \\
\hline & 6 & The target users of the guideline are clearly defined \\
\hline \multirow{8}{*}{$\begin{array}{l}\text { 3: } \quad \text { Rigor } \\
\text { Development }\end{array}$} & 7 & Systematic methods were used to search for evidence \\
\hline & 8 & $\begin{array}{l}\text { The criteria for selecting the evidence are clearly } \\
\text { described }\end{array}$ \\
\hline & 9 & $\begin{array}{l}\text { The strengths and limitations of the body of evidence are } \\
\text { clearly described }\end{array}$ \\
\hline & 10 & $\begin{array}{l}\text { The methods for formulating the recommendations are } \\
\text { clearly described }\end{array}$ \\
\hline & 11 & $\begin{array}{l}\text { The health benefits, side effects and risks are considered } \\
\text { in formulating the recommendations }\end{array}$ \\
\hline & 12 & $\begin{array}{l}\text { There is an explicit link between the recommendations } \\
\text { and the supporting evidence }\end{array}$ \\
\hline & 13 & $\begin{array}{l}\text { The guideline has been externally reviewed by experts } \\
\text { prior to its publication }\end{array}$ \\
\hline & 14 & A procedure for updating the guideline is provided \\
\hline \multirow{3}{*}{$\begin{array}{l}\text { 4: } \quad \text { Clarity } \\
\text { Presentation }\end{array}$} & 15 & The recommendations are specific and unambiguous \\
\hline & 16 & $\begin{array}{l}\text { The different options for management of the condition or } \\
\text { health issue are clearly presented }\end{array}$ \\
\hline & 17 & Key recommendations are easily identifiable \\
\hline \multirow[t]{4}{*}{ 5: Applicability } & 18 & $\begin{array}{l}\text { The guideline describes facilitators and barriers to its } \\
\text { application }\end{array}$ \\
\hline & 19 & $\begin{array}{l}\text { The guideline provides advice and/or tools on how the } \\
\text { recommendations can be put into practice }\end{array}$ \\
\hline & 20 & $\begin{array}{l}\text { The potential resource implications of applying the } \\
\text { recommendations have been considered }\end{array}$ \\
\hline & 21 & The guideline presents monitoring and/or auditing criteria \\
\hline \multirow[t]{2}{*}{$\begin{array}{l}\text { 6: Editorial } \\
\text { Independence }\end{array}$} & 22 & $\begin{array}{l}\text { The views of the funding body have not influenced the } \\
\text { content of the guideline. }\end{array}$ \\
\hline & 23 & $\begin{array}{l}\text { Competing interests of guideline development group } \\
\text { members have been recorded and addressed }\end{array}$ \\
\hline \multirow{2}{*}{\multicolumn{2}{|c|}{$\begin{array}{ll}\begin{array}{l}\text { Overall } \\
\text { assessment }\end{array} & \text { guideline } \\
\end{array}$}} & Rate the overall quality of this guideline \\
\hline & & I would recommend this guideline for use \\
\hline
\end{tabular}


Table 2 Summary and features of included bereavement care practice guidelines

\begin{tabular}{|c|c|c|c|}
\hline $\begin{array}{l}\text { Bereavement care practice guideline title } \\
\text { and reference }\end{array}$ & $\begin{array}{l}\text { Country and } \\
\text { scope }\end{array}$ & Developed by & Developed for \\
\hline Bereavement care service standards ${ }^{24}$ & UK, national & $\begin{array}{l}\text { Cruse Bereavement Care (Cruse) and } \\
\text { the Bereavement Services Association } \\
\text { (BSA) }\end{array}$ & $\begin{array}{l}\text { Professionals working in any sector } \\
\text { of bereavement care }\end{array}$ \\
\hline Shaping Bereavement Care ${ }^{25}$ & $\begin{array}{l}\text { UK (Scotland), } \\
\text { national }\end{array}$ & $\begin{array}{l}\text { Scottish Government Health } \\
\text { Directorate }\end{array}$ & Service provision by NHS Scotland \\
\hline $\begin{array}{l}\text { Palliative Care Bereavement Support } \\
\text { Guidelines }{ }^{26}\end{array}$ & $\begin{array}{l}\text { New Zealand, } \\
\text { organizational }\end{array}$ & $\begin{array}{l}\text { Mid-Central District Health Board } \\
\text { (MDHB) Palliative Care Bereavement } \\
\text { Support Group }\end{array}$ & Professionals working in the MDHB \\
\hline $\begin{array}{l}\text { Recommend Guiding Principles for Effective } \\
\text { Suicide Bereavement Support Groups }{ }^{27}\end{array}$ & $\begin{array}{l}\text { USA, } \\
\text { organizational }\end{array}$ & $\begin{array}{l}\text { American Association of Suicide- } \\
\text { ology }\end{array}$ & Suicide support groups \\
\hline $\begin{array}{l}\text { Bereavement Care Following Pregnancy } \\
\text { Loss and Perinatal Death }{ }^{28}\end{array}$ & Ireland, national & $\begin{array}{l}\text { Health Service Executive (Ireland's } \\
\text { Health Service) }\end{array}$ & Maternity settings \\
\hline $\begin{array}{l}\text { Bereavement support standards for specialist } \\
\text { palliative care services } 29\end{array}$ & $\begin{array}{l}\text { Australia, } \\
\text { organizational }\end{array}$ & $\begin{array}{l}\text { Department of Health, State } \\
\text { Government of Victoria, Melbourne }\end{array}$ & $\begin{array}{l}\text { Professionals working in state } \\
\text { government-funded, adult, specialist } \\
\text { palliative care services }\end{array}$ \\
\hline $\begin{array}{l}\text { Policy of Bereavement Care Anglia Cancer } \\
\text { Network } 30\end{array}$ & UK, regional & Anglia Cancer Network & $\begin{array}{l}\text { Members of the Bereavement Care } \\
\text { Anglia Cancer Network }\end{array}$ \\
\hline $\begin{array}{l}\text { Clinical practice guidelines for the } \\
\text { Psychosocial and Bereavement Support of } \\
\text { Family Caregivers of Palliative Care Patients } \\
31\end{array}$ & Australia, national & $\begin{array}{l}\text { Researchers from University of } \\
\text { Melbourne, St Vincent’s Hospital } \\
\text { Melbourne, Beyond Blue }\end{array}$ & $\begin{array}{l}\text { Professionals caring for adult } \\
\text { palliative patients throughout } \\
\text { Australia }\end{array}$ \\
\hline $\begin{array}{l}\text { Standards and guidelines for suicide } \\
\text { bereavement support groups } 32\end{array}$ & $\begin{array}{l}\text { Australia, } \\
\text { organizational }\end{array}$ & $\begin{array}{l}\text { Lifeline, Suicide Bereavement Support } \\
\text { Groups }\end{array}$ & $\begin{array}{l}\text { Suicide Bereavement Support } \\
\text { Groups }\end{array}$ \\
\hline Bereavement Principles ${ }^{33}$ & UK, national & British Banking Association (BBA) & $\begin{array}{l}\text { For employees working with clients } \\
\text { of BBA }\end{array}$ \\
\hline Sands Principles of Bereavement Care ${ }^{34}$ & UK, national & $\begin{array}{l}\text { Sands - Stillbirth and neonatal death } \\
\text { charity }\end{array}$ & Professionals \\
\hline
\end{tabular}


Winston’s Wish Charter for Bereaved Children ${ }^{35}$

Childhood Bereavement Principles ${ }^{36}$

Guidelines for Loss Support of Dying Children \& Their Families ${ }^{37}$

SANE Bereavement Guidelines ${ }^{38}$

Responding to Grief, Trauma, and Distress

After a Suicide: U.S. National Guidelines ${ }^{39}$
UK, organizational

Ireland, national

Canada,

organizational

Australia,

organizational

USA,

organizational
Professionals working with bereaved children/adolescents

ICBN members

Irish Childhood Bereavement Network (IBCN)

British Columbia's Children's \&

Women's Health Centre, Canuck Place Children's Hospice

Professionals working within the developing organisations

SANE mental illness and bereavement project

Bereavement support professionals for people affected by mental illness/suicide

Anyone who is in contact with, cares about, or wishes to help those impacted by a suicide loss. 
Table 1 Summary of domain scores (expressed as \% of maximum score) for bereavement care practice guidelines according to Agree II

\begin{tabular}{|c|c|c|c|c|c|c|c|c|c|c|}
\hline & \multicolumn{7}{|c|}{ AGREE II Instrument } & \multicolumn{3}{|c|}{$\begin{array}{c}\text { Additional quality } \\
\text { assessment }\end{array}$} \\
\hline & $\begin{array}{c}\text { Domai } \\
\text { n } 1 \\
\text { Scope } \\
\text { and } \\
\text { purpose }\end{array}$ & $\begin{array}{c}\text { Domain } 2 \\
\text { Stakeholde } \\
r \\
\text { involvemen } \\
t\end{array}$ & $\begin{array}{c}\text { Domain } 3 \\
\text { Rigor of } \\
\text { developmen } \\
t\end{array}$ & $\begin{array}{c}\text { Domain } 4 \\
\text { Clarity of } \\
\text { presentatio } \\
n\end{array}$ & $\begin{array}{c}\text { Domain } 5 \\
\text { Applicabilit } \\
y\end{array}$ & $\begin{array}{c}\text { Domain } 6 \\
\text { Editorial } \\
\text { independenc } \\
e\end{array}$ & $\begin{array}{l}\text { Additional } \\
\text { Items } \\
\text { Overall quality } \\
\text { score (1-7); } \\
\text { Recommendatio } \\
\text { n for use } \ddagger\end{array}$ & $\begin{array}{c}\text { Mean } \\
\text { guidelin } \\
\text { e score } \\
\text { mean } \\
\text { (SD) }\end{array}$ & $\begin{array}{l}\text { Overall } \\
\text { Quality } \\
\text { Rating\$ }\end{array}$ & ICC \\
\hline 24 & 52.8 & 55.6 & 13.5 & 52.8 & 10.4 & 29.2 & 2.5; No & $\begin{array}{c}35.7 \\
(20.8)\end{array}$ & Low & $\begin{array}{c}0.95 \\
(0.89 \\
- \\
0.98)\end{array}$ \\
\hline 25 & $63.9 \dagger$ & $69.4 \dagger$ & 18.8 & $83.3 \dagger$ & 29.2 & 12.5 & 4.5; Mod & $\begin{array}{c}46.2 \\
(29.7)\end{array}$ & $\begin{array}{c}\text { Averag } \\
\text { e }\end{array}$ & $\begin{array}{c}0.96 \\
(0.92 \\
- \\
0.98)\end{array}$ \\
\hline 26 & $97.2 \dagger$ & $69.4 \dagger$ & $80.2 \dagger$ & $94.4 \dagger$ & 58.3 & 0 & 6; Yes & $\begin{array}{c}66.6 \\
(35.8)\end{array}$ & $\begin{array}{c}\text { Averag } \\
\text { e }\end{array}$ & $\begin{array}{c}0.97 \\
(0.93 \\
- \\
0.98)\end{array}$ \\
\hline 27 & $75 \dagger$ & 30.6 & 4.2 & 36.1 & 33.3 & 0 & 2.5; No & $\begin{array}{c}29.9 \\
(27.0)\end{array}$ & Low & $\begin{array}{c}0.97 \\
(0.94 \\
- \\
0.99)\end{array}$ \\
\hline 28 & $100 \dagger$ & 55.6 & 39.6 & $100 \dagger$ & 22.9 & 0 & 4.5; Mod & $\begin{array}{c}53.0 \\
(40.8)\end{array}$ & Low & $\begin{array}{c}0.99 \\
(0.97 \\
- \\
0.99)\end{array}$ \\
\hline
\end{tabular}




\begin{tabular}{|c|c|c|c|c|c|c|c|c|c|c|}
\hline \multirow[b]{2}{*}{29} & \multirow[b]{2}{*}{$80.6 \dagger$} & \multirow[b]{2}{*}{58.3} & \multirow[b]{2}{*}{24} & \multirow[b]{2}{*}{$100 \dagger$} & \multirow[b]{2}{*}{$64.6 \dagger$} & \multirow[b]{2}{*}{25} & \multirow[b]{2}{*}{ 5.5; Yes } & \multirow[b]{2}{*}{$\begin{array}{c}58.8 \\
(30.2)\end{array}$} & \multirow[b]{2}{*}{$\begin{array}{c}\text { Averag } \\
\text { e }\end{array}$} & \multirow[b]{2}{*}{$\begin{array}{c}0.89 \\
(0.75 \\
- \\
0.95)\end{array}$} \\
\hline & & & & & & & & & & \\
\hline 30 & $100 \dagger$ & 50 & 24 & $100 \dagger$ & $70.8 \dagger$ & 0 & 4.5; Mod & $\begin{array}{c}69.0 \\
(32.8)\end{array}$ & $\begin{array}{c}\text { Averag } \\
\text { e }\end{array}$ & $\begin{array}{c}0.97 \\
(0.94 \\
- \\
0.98)\end{array}$ \\
\hline 31 & $100 \dagger$ & $91.7 \dagger$ & $82.3 \dagger$ & $100 \dagger$ & $62.5 \dagger$ & 25 & 6; Yes & $\begin{array}{c}76.9 \\
(29.0)\end{array}$ & High & $\begin{array}{c}0.96 \\
(0.90 \\
- \\
0.98)\end{array}$ \\
\hline 32 & $86.1 \dagger$ & 41.7 & 4.2 & $100 \dagger$ & 56.3 & 37.5 & 2.5; Mod & $\begin{array}{c}54.3 \\
(34.8)\end{array}$ & Low & $\begin{array}{c}0.98 \\
(0.97 \\
- \\
0.99)\end{array}$ \\
\hline 33 & 2.8 & 2.8 & 0 & 47.2 & 12.5 & 0 & 1; No & $\begin{array}{c}10.9 \\
(18.4)\end{array}$ & Low & $\begin{array}{c}0.93 \\
(0.84 \\
- \\
0.97)\end{array}$ \\
\hline 34 & 11.1 & 11.1 & 0 & 58.3 & 0 & 0 & 1; No & $\begin{array}{c}13.4 \\
(22.7)\end{array}$ & Low & $\begin{array}{c}0.98 \\
(0.95 \\
- \\
0.99)\end{array}$ \\
\hline 35 & 8.3 & 22.2 & 0 & 41.7 & 0 & 0 & 1; No & $\begin{array}{c}12.0 \\
(16.9)\end{array}$ & Low & $\begin{array}{c}0.98 \\
(0.96 \\
- \\
0.99)\end{array}$ \\
\hline 36 & 13.9 & 8.3 & 5.2 & 16.7 & 14.6 & 8.3 & 1; No & $\begin{array}{l}11.2 \\
(4.5)\end{array}$ & Low & $\begin{array}{c}0.93 \\
(0.84 \\
- \\
0.97)\end{array}$ \\
\hline
\end{tabular}




\begin{tabular}{|c|c|c|c|c|c|c|c|c|c|c|}
\hline \multirow[b]{2}{*}{37} & \multirow[b]{2}{*}{$86.1 \dagger$} & \multirow[b]{2}{*}{22.2} & \multirow[b]{2}{*}{0} & \multirow[b]{2}{*}{55.6} & \multirow[b]{2}{*}{14.6} & \multirow[b]{2}{*}{0} & \multirow[b]{2}{*}{ 2.5; No } & \multirow[b]{2}{*}{$\begin{array}{c}29.8 \\
(34.4)\end{array}$} & \multirow[b]{2}{*}{ Low } & \\
\hline & & & & & & & & & & $\begin{array}{c}0.98 \\
(0.95 \\
- \\
0.99)\end{array}$ \\
\hline 38 & $100 \dagger$ & 30.6 & 7.3 & $66.7 \dagger$ & 29.2 & 0 & 3.5; No & $\begin{array}{c}39.0 \\
(37.9)\end{array}$ & Low & $\begin{array}{c}0.98 \\
(0.96 \\
- \\
0.99)\end{array}$ \\
\hline 39 & $100 \dagger$ & 54.2 & 26.2 & $83.3 \dagger$ & 37.5 & 0 & 4.5; Mod & $\begin{array}{c}50.2 \\
(37.0)\end{array}$ & Low & $\begin{array}{c}0.95 \\
(0.89 \\
- \\
0.98)\end{array}$ \\
\hline $\begin{array}{c}\text { Total } \\
\text { Domai } \\
\text { n Score } \\
\text { mean } \\
(\mathrm{SD})\end{array}$ & $\begin{array}{c}67.4 \\
(37.5)\end{array}$ & $42.1(25.2)$ & $20.6(26.4)$ & $71.0(27.6)$ & 32.3 (23.7) & 9.2 (13.3) & & $\begin{array}{c}41.0 \\
(28.3)\end{array}$ & & \\
\hline
\end{tabular}

Data are expressed as a percentage of maximum score (\%) except overall quality score (point score between 1-7) and ICC. SD=standard deviation ‡ Overall guideline recommendation option to the statement: "I would recommend this guideline for use" with three response options: Yes, Yes with modifications (Mod), No. Domain scores $\geq 80 \%=$ good; $60-79 \%=$ acceptable; $40-59 \%=l o w ;<40 \%=v e r y$ low. $\dagger=$ total domain score $>60 \%$. \$ Overall quality: objective categorization where high quality is defined when 5 or more domains scored $>60 \%$, average quality when 3 or 4 domains scored $>60 \%$ and low-quality when $\leq 2$ domains scored $>60 \%{ }^{20}$; Intra-class correlations coefficient (ICC; including upper and lower bounds) showing inter-rater reliability for total domain scores. 